\title{
RESISTÊNCIA DO MILHO (Zea mays L.) TRANSGÊNICO (Bt) À LAGARTA-DO- CARTUCHO, Spodoptera frugiperda (Smith) (LEPIDOPTERA: NOCTUIDAE)
}

\author{
JOSÉ M. WAQUIL ${ }^{1}$, FRANCYS M. FERREIRA VILLELA², JOHN E. FOSTER ${ }^{3}$
}

\author{
${ }^{1}$ Pesquisador, Embrapa Milho e Sorgo/Bolsista CNPq. Caixa Postal 151, CEP. 35701-970 Sete Lagoas, MG. E-mail: \\ waquil@cnpms.embrapa.br (autor para correspondência) \\ ${ }^{2}$ Departamento de Biologia Animal, Universidade Federal de Viçosa. CEP. 36571-000 Viçosa, MG. \\ ${ }^{3}$ Department of Entomology/UN-L, 202 Plant Industry Bldg., Lincoln, NE 68583-0816
}

Revista Brasileira de Milho e Sorgo, v.1, n.3, p.1-11, 2002

\begin{abstract}
RESUMO - No Brasil, a utilização de milho transgênico (Bt) pode reduzir perdas causadas por vários lepidópteros-pragas, equivalentes a aproximadamente 500 milhões de dólares anuais. O objetivo deste trabalho foi avaliar os híbridos de milho $B t$ disponíveis no mercado americano para resistência à lagarta-do-cartucho do milho (LCM), Spodoptera frugiperda (Smith) (Lepidoptera: Noctuidae). Nove híbridos de milho Bt expressando as toxinas Cry 1F, Cry 1A(b), Cry 1 A(c) e Cry 9C, além de um híbrido (MP 704 X 707) expressando resistência natural para a LCM, foram comparados num experimento, em campo, em blocos ao acaso, com parcela subdividida e quatro repetições. Nas parcelas, foram comparados os dez híbridos e, nas subparcelas, as versões $B t$ versus não- $B t$, ou híbrido com resistência natural versus susceptível. A infestação artificial foi realizada 33 dias após a semeadura e as avaliações basearam-se no número de larvas sobreviventes, aos 10 e 15 dias após a infestação, peso das larvas sobreviventes e notas de danos nas plantas. Para todas as variáveis estudadas, os resultados demonstraram diferenças significativas $(\mathrm{P} \leq 0,05)$ entre os híbridos avaliados. Também as testemunhas não-Bts diferiram significativamente dos respectivos híbridos $B t \mathrm{~s}$, exceto para aqueles expressando a toxina Cry 9C. O híbrido 2722 IMI, expressando a toxina Cry $1 \mathrm{~F}$, foi o mais resistente (imune) e os híbridos expressando a toxina Cry $1 \mathrm{~A}(\mathrm{~b})$ e a resistência natural foram moderadamente resistentes. Em geral, os híbridos transgênicos resistentes produziram cerca de $32 \%$ a mais de grãos que as testemunhas suscetíveis.
\end{abstract}

Palavras-chave: Insecta, biologia, manejo de pragas, biotecnologia, imunidade.

\section{RESISTANCE OF BT TRANSGENIC MAIZE (Zea mays L.) TO FALL ARMYWORM, Spodoptera frugiperda (SMITH) (LEPIDOPTERA: NOCTUIDAE)}

\begin{abstract}
In Brazil, the use of transgenic maize $(B t)$ might reduce the yield loss caused by insect pest, equivalent to 500 million dollars. The objective was to evaluate the $B t$ maize hybrids available in the American market to fall armyworm (FAW), Spodoptera frugiperda (Smith) (Lepidoptera: Noctuidae), resistance. Nine maize hybrids, expressing the Cry 1F, Cry 1A(b), Cry $1 \mathrm{~A}$ (c) and Cry 9C Bt toxins and one native resistance hybrid (MP 704 X 707) were compared, in the field, with susceptible pairs in a completed randomized block design with split plot and 4 replications. The artificial infestation was implemented 33 days after planting and the evaluations were based on the number of surviving larvae at 10 and 15 days after infestation, larval weight and leaf damage score. All studied variables indicated significant differences $(\mathrm{P} \leq 0,05)$ among the hybrids. Also, significant differences were observed between
\end{abstract}


some $B t$ maize and the controls, except for the maize hybrid expressing Cry $9 \mathrm{C}$ toxin. The hybrid 2722 IMI, expressing the toxin Cry 1F, was the most resistant cultivar (immune) and the ones expressing the Cry $1 \mathrm{~A}(\mathrm{~b})$ toxin and the native resistance were intermediate. In general, the transgenic maize hybrids yielded $32 \%$ more than the susceptible non- $B t$.

Key words: Insecta, biology, pest management, biotechnology, immunity.

A lagarta-do-cartucho do milho (LCM), Spodoptera frugiperda (Smith) pode causar perdas de 17 a 38,7\% na produção, tanto no milho como no sorgo, dependendo do ambiente, da cultivar e, principalmente, do estádio de desenvolvimento enutricional das plantas atacadas (Carvalho, 1970; Cruz \& Turpin, 1983; Williams \& Davis, 1990; Cortez \& Waquil, 1997; Cruz et al. 1999). Para o manejo dessa praga, são recomendadas várias estratégias, incluindo métodos culturais, biológicos e químicos.

A resistência genética, através da seleção natural ou dirigida, vem sendo intensivamente utilizada pelo homem, no controle de pragas e doenças, desde que as plantas foram domesticadas, há mais de 11 mil anos (Harlan, 1975). Na literatura, há registro de várias fontes de resistência genética do milho a pragas. Destacam-se, como fontes de resistência à $S$. frugiperda, os genótipos do grupo Antigua. Com resistência múltipla a várias espécies de Lepidóptera, vêm sendo citados os genótipos 2D118, MpSWCB-4, Pio. X304C, Zapalote Chico 2451 e MP 701 a 707, Zapalote Chico e TL 87-A1855-7. Milhos tropicais, como CMS 23, CMS $14 \mathrm{C}$ e CMS 24 foram os menos danificados, em uma coleção de 64 entradas avaliadas em Sete Lagoas, MG (Viana \& Gama, 1988). Antibiose e nãopreferência são os mecanismos de resistência à $S$. frugiperda observados nessas fontes (Viana \& Potenza, 1992 e Davis \& Williams, 1997). O conteúdo de hemicelulose tem sido relacionado com a resistência à $S$. frugiperda, mas não com a resistência à Ostrinia nubilalis (Hedin et al., 1996; Williams et al., 1998a). Nos EUA e no México, linhas de milho com resistência múltipla para outras espécies, como Diatraea grandiosella e $S$. frugiperda, têm sido liberadas (Williams \& Davis, 1982; 1984; Williams et al., 1990). Nos últimos 15 anos, mais de 30 cultivares de milho resistentes à $S$. frugiperda e a outras pragas foram registradas e distribuídas. Entretanto, a maioria dessas fontes de resistência é proveniente do grupo Antigua e tem a base genética muito estreita (Williams et al., 1997). Não têm sido encontradas outras fontes com alto nível de resistência à lagarta-do-cartucho.

Recentemente, com o desenvolvimento das técnicas de engenharia genética viabilizando, inclusive, a transformação do milho, aumentou drasticamente o conjunto de genes disponíveis para serem utilizados como fonte de resistência, incluindo espécies evolutivamente distantes (Williams et al., 1997). Isto quebra o paradigma até então utilizado na pesquisa de resistência de plantas a agentes bióticos (Foster \& Ramnath, 1997). Esforços têm sido feitos para desenvolver plantas expressando o gene $b t$, clonado da bactéria Bacillus thuringiensis (Berliner) (Bt), que codifica uma proteína tóxica (Boulder, 1993). Essa bactéria produz a $\beta$-exotoxina e a $\delta$-endotoxina, ambas com ação tóxica sobre um grande número de espécies de insetos (Ignoffo \& Gregory, 1972; Dulmage, 1980). O gene codificador da $\delta$-endotoxina, CryIA(b), clonado do $B t$, foi introduzido com sucesso pela primeira vez em planta de fumo (Vaeck et al., 1987). Nos EUA, várias companhias de semente têm produzido híbridos de milho transgênico, expressando a proteína tóxica $\delta$ endotoxina para resistência às duas gerações de $O$. nubilalis Hübner (Barry \& Darrah, 1997; Sagers et al., 1997; Estruch et al., 1997), os quais vêm sendo 
anualmente avaliados. Como as cultivares transgênicas de milho estão sendo desenvolvidas e comercializadas pelas empresas privadas, será necessária uma avaliação eficiente desses híbridos, realizada por instituições públicas (Barry \& Darrah, 1997). Entretanto, poucos estudos têm sido conduzidos para se avaliar a reação de milhos transgênicos em relação às pragas importantes para a agricultura brasileira.

As toxinas do $B t$ são altamente específicas na sua atividade e, portanto, quando utilizadas não apresentam riscos para outros organismos (Vaeck et al., 1987). Como bioinseticida, o Bt vem sendo usado há décadas (Feitelson et al., 1992) e está registrado, sem limitação de uso, para o controle de várias espécies de Lepidoptera. A limitação para sua maior participação no mercado se deve ao alto custo de produção e à instabilidade dos resultados obtidos no campo (Vaeck et al., 1987). Mesmo sendo o $B t$ efetivo no controle de várias espécies-praga do milho, conforme seu registro de uso, a eficiência das estirpes hoje comercializadas (HD-1) sobre a lagarta-do-cartucho é baixa (Waquil et al., 1982).

Embora os bioinseticidas à base de $B t$ não tenham dado bons resultados no controle de $S$. frugiperda, tem-se observado que plantas transgênicas com o gene $b t$ apresentam algum nível de resistência a essa espécie. Comparando-se as versões transgênicas com as normais, de oito híbridos simples de milho da Northrup King, avaliados para resistência à $S$. frugiperda e D. grandiosella, tanto em teste de campo como em bioensaios, Williams et al. (1997) verificaram que a área foliar destruída, a sobrevivência e o desenvolvimento dos insetos foram significativamente menores nos híbridos transgênicos. Os autores concluíram que a expressão do gene $b t$, CryIA(b), produziu características de alta resistência à $S$. frugiperda e quase imunidade à $D$. grandiosella. Esse mesmo gene, expressando a proteína tóxica em híbridos de milho da
Novartis, causou $100 \%$ de mortalidade a larvas de D. grandiosella, quando alimentadas com dietas contendo palha (bráctea da espiga) liofilizada (Williams et al., 1998b). Neste trabalho, foram observados também $100 \%$ de mortalidade de Helicoverpa zea (Boddy), nesse mesmo tipo de ensaio. Substituindo-se a palha liofilizada por estilos-estigmas da inflorescência do milho transgênico, na dieta artificial, notou-se alta mortalidade de $H$. $z e a$ e os insetos sobreviventes apresentaram redução significativa do crescimento. Nesse tipo de ensaio, $S$. frugiperda foi menos suscetível à toxina do $B t$, mas foi observada redução de $40 \%$ na sobrevivência e de $94 \%$ na biomassa das larvas alimentadas em dietas contendo palha (liofilizada) de milho transgênico (Williams et al., 1998b). Nas dietas contendo apenas estilo-estigma de milho transgênico, não se observou mortalidade, mas notou-se redução significativa no desenvolvimento dos insetos (Williams et al., 1998a). Aumento significativo no nível de resistência do milho à S. frugiperda foi obtido pelo cruzamento de linhas com genes de resistência natural do "pool" gênico da espécie com linhas expressando o gene bt (Maredia, 1997; Williams et al., 1999). Portanto, a liberação de híbridos de milho expressando os dois tipos de resistência poderá reduzir significativamente os danos causados por $S$. frugiperda e também reduzir a taxa de seleção de biótipos do inseto que venham a quebrar essa resistência. O objetivo foi avaliar o potencial da utilização dos híbridos de milho transgênicos disponíveis no mercado (com o gene $b t$ ) em comparação com os genes nativos, para resistência à $S$. frugiperda.

\section{Material e Métodos}

Para avaliar a resistência do milho transgênico, expressando as toxinas do Bt. Cry $1 \mathrm{~F}$, Cry 1 A(b), Cry 1 A(c) e Cry 9C, foi instalado um ensaio no dia 11 de maio de 2000, em Nebraska, 
nos EUA. O experimento foi conduzido em campo, seguindo a metodologia adotada por Williams et al., (1997 e 1999), com pequenos ajustes, em função das variações temporal e espacial. Foram utilizados nove híbridos de milho transgênico, com algumas das respectivas versões não-transgênicas e um híbrido de milho com resistência natural à LCM e mais um híbrido suscetível como testemunha. Em alguns dos casos, como não se obtiveram as duas versões $B t \mathrm{e}$ não- $B t$ do mesmo híbrido; foram utilizados como controle versões com diferentes bases genéticas, como indicado em cada gráfico. O ensaio foi conduzido segundo as recomendações técnicas para a região, num delineamento em blocos completos ao acaso, com parcelas subdivididas e quatro repetições. Os híbridos foram semeados nas parcelas e as versões $B t$ versus não- $B t$, nas subparcelas, com duas linhas de $5 \mathrm{~m}$, espaçadas de $1 \mathrm{~m}$. Foi também utilizado o híbrido Mp 704 X Mp 707, com resistência natural (não transgênico) e uma testemunha susceptível Ab 24E X Sc 229 (Williams et al., 1999).

Utilizando a metodologia proposta por Mihm(1989), cada planta foi infestada artificialmente com aproximadamente 50 larvas recém-eclodidas da LCM, através de duas aplicações, nos dias 15 e 16 de junho. Aos 10 e 15 dias após a infestação, quatro plantas/parcela foram amostradas ao acaso, dissecadas, e o número de larvas sobreviventes foi anotado. Das larvas sobreviventes coletadas no campo, a maior de cada planta teve sua biomassa estimada em balança de precisão. Os danos foliares causados pelas lagartas foram estimados através de uma escala visual de notas variando de 0 (sem danos) a 9 (cartucho totalmente destruído) (Williams et al., 1983), no dia 6 de julho. Os dados obtidos foram submetidos à análise de variância e as médias, separadas pelo "Duncan Multiple Range Test", com $\mathrm{P} \leq 0.05$.

\section{Resultados e Discussão}

Os resultados mostraram interação significativa entre os híbridos expressando as diferentes toxinas do $B t$ e as versões $B t$ s versus não- $B t$ s. Portanto, as comparações foram feitas somente entre os híbridos $B t$ s e as versões $B t$ s versus não- $B t$ s, para cada híbrido individualmente. Foram observadas diferenças significativas entre a maioria dos híbridos de milho e as respectivas testemunhas, para a maioria das variáveis avaliadas. Não foi observada diferença significativa $(\mathrm{P} \leq 0.05)$ entre as versões $B t$ (Cry 9C) e não- $B t$ dos híbridos Garst 8481 e Garst 8539. Relativo à produção de grãos, os híbridos transgênicos produziram mais que as respectivas testemunhas, com exceção dos híbridos Garst 8481 e Garst 8539 expressando a toxina Cry 9C. Sabe-se que a produtividade é função de múltiplas variáveis, o que determina o potencial genético de cada genótipo e respostas diferenciadas para cada interação.

Sobrevivência de larvas - O número médio de larvas da LCM sobreviventes/planta reduz-se naturalmente (mortalidade natural, canibalismo, inimigos naturais, etc), mesmo nos hospedeiros mais suscetíveis. Assim, partindo de uma média de 50 larvas/ planta colocadas inicialmente, as testemunhas já apresentavam em torno de 8 larvas/planta, aos 10 dias, e 4 larvas/planta, aos 15 dias após a infestação. Tanto aos dez como aos 15 dias após a infestação, observaram-se diferenças significativas entre os híbridos quanto ao número médio de larvas sobreviventes (Figuras 1 e 2). Como no tratamento 2722 IMI (Cry 1F), o número de insetos vivos observados, aos 15 dias após a infestação, foi nulo, os demais tratamentos foram comparados à constante zero, pelo teste de t. Para essa comparação, foi assumido que nenhum inseto dessa espécie sobreviveu neste híbrido $B t$.

Do elenco de híbridos de milho, Bt ou com resistência (natural) avaliados, notaram-se três grupos: altamente resistentes - híbridos 2722 IMI, Pioneer 34G82, 34K87 e o DK 551, nos quais o número médio de larvas sobreviventes aos 10 e 15 dias após a infestação foi inferior a 0,8 ; moderadamente 


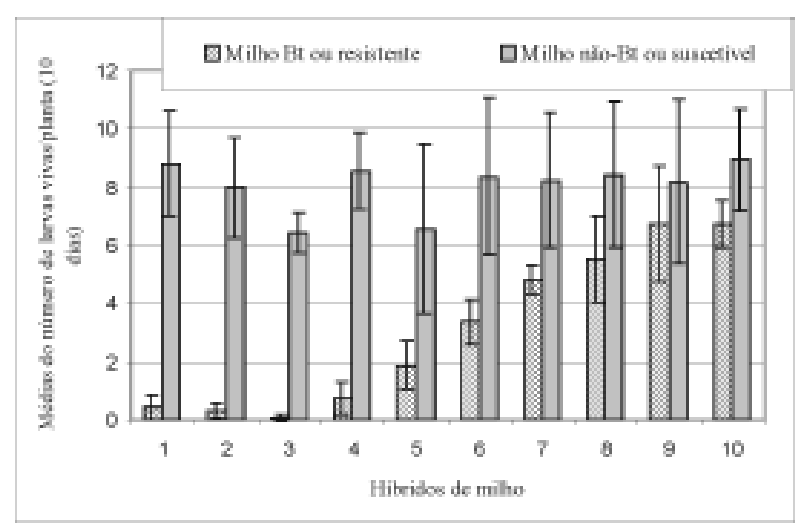

FIGURA 1. Médias ( \pm erro padrão) do número de larvas vivas, por planta de milho, coletadas dez dias após a infestação, dos híbridos Bts: 1-2722 IMI (Cry 1F); 2-P 34G82 (Cry 1Ab); 3-P34K87 (Cry 1Ab); 4-DK 551 (Cry 1Ab); 5-MP 704 X MP707 (resistência natural); 6-2717 IMI (Cry 1Ab); 7-M 454R80 (Cry 1Ac); 8-DK 618 (Cry 1Ac); 9-Garst 8481(Cry 9C); 10 Garst 8539 (Cry 9C) e dos nãoBts: 1-2722 IMI; 2 a 4-P 3162; 5-Ab42E X SC 229 (suscetível); 6 a 8-P 3162; 9-Garst 8481 e 10Garst 8539, sob infestação artificial da lagarta-docartucho do milho, Lincoln, NE, 2000.

resistentes - MP 704 x MP 707, 2717 IMI e Max 454R80, cujas médias variaram de 1,2 a 3,8 larvas vivas/planta nas duas amostragens e suscetíveis DK618 e os híbridos Garst 8481 e 8539, nos quais foram encontradas médias de 3,9 a 6,8 larvas vivas/ planta (Tabela 1). No híbrido com resistência natural, embora tenha-se observado, na avaliação realizada aos 15 dias, número de larvas sobreviventes equivalente ao do grupo dos altamente resistentes, ele foi incluído entre os intermediários, com base nas outras variáveis analisadas. No grupo dos híbridos suscetíveis, não houve diferença significativa entre os milhos transgênicos e as testemunhas suscetíveis (Figura 1 e 2). Williams et al. (1997 e 1998b) observaram redução no número de larvas sobreviventes nos genótipos de milho expressando a toxina do Bt. Cry 1 A(b). Nota-se, ainda, interação entre eventos e genótipos, pois as mesmas toxinas Cry $1 \mathrm{Ab} e$ 1Ac expressas em híbridos diferentes produziram resultados significativamente diferentes quanto à sobrevivência e desenvolvimento larval (Tabela 1).

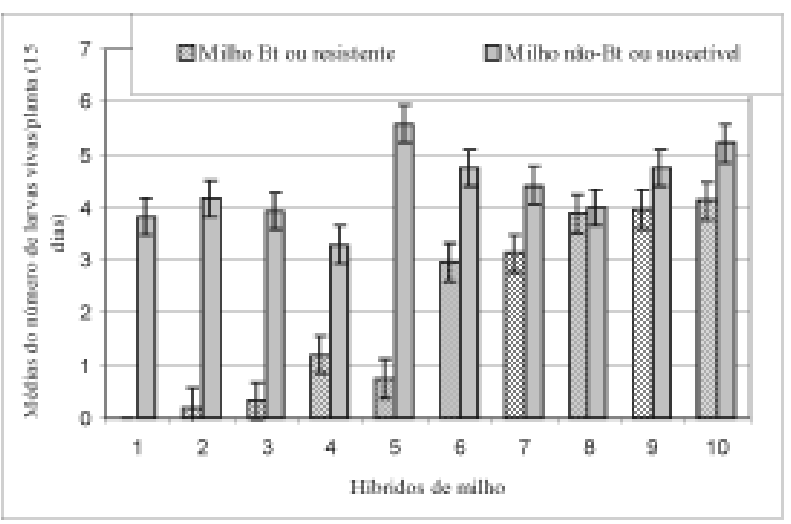

FIGURA 2. Médias ( \pm erro padrão) do número de larvas vivas, por planta de milho, coletadas 15 dias após a infestação, dos híbridos Bts: 1-2722 IMI(Cry 1F); 2-P 34G82 (Cry 1Ab); 3-P34K87 (Cry 1Ab); 4-DK 551 (Cry 1Ab); 5-MP 704 X MP707 (resistência natural); 6-2717 IMI (Cry 1Ab); 7-M 454R80 (Cry 1Ac); 8-DK 618 (Cry 1Ac); 9-Garst 8481(Cry 9C); 10 Garst 8539 (Cry 9C) e dos nãoBts: 1-2722 IMI; 2 a 4-P 3162; 5-Ab42E X SC 229 (suscetível); 6 a 8-P 3162; 9-Garst 8481 e 10 Garst 8539, sob infestação artificial da lagarta-docartucho do milho, Lincoln, NE, 2000.

Biomassa das larvas sobreviventes - Nos milhos transgênicos, a biomassa das maiores larvas encontradas em cada parcela, aos 15 dias após a infestação, variou de 0 (zero) no híbrido 2722 IMI (Cry 1F) a 586,4 mg, no híbrido Garst 8481 (Cry 9C) (Tabela 1). A média da biomassa por lagarta nos híbridos não- $B t$ ou suscetível variou de cerca de 150 a 250 mg no híbrido Pioneer 3162, usado como testemunha (Figura 3 ). Como no item anterior, a biomassa das lagartas sobreviventes no tratamento 2722 IMI (Cry 1F) foi nula. Os dados dessa variável não foram incluídos na análise de variância e os demais tratamentos foram comparados entre si, pelo teste de Duncan $(\mathrm{P} \leq 0,05)$ e à constante zero, pelo teste de $t$, assumindo-se que, nesse tratamento, não há sobrevivência de larvas dessa espécie. 
TABELA 1. Média do número e da biomassa de Spodoptera frugiperda (Smith) sobreviventes em milho $B t$, bem como as respectivas estimativas de danos, avaliados através de escala visual de notas, e peso de grãos corrigidos para 13\% de umidade, Lincoln, NE, 2000.

\begin{tabular}{lccccc}
\hline Hibrido & \multicolumn{2}{c}{ Dias após infestação } & Biomassa $^{1}$ & Notas $^{1}$ & Produtividade $^{1}$ \\
\cline { 2 - 3 } & 10 & 15 & $(\mathbf{m g})$ & danos & (t ha $^{-1}$ ) \\
\hline 2722 IMI(Cry 1F) & $0,4 \mathrm{ab}$ & $0,0^{2}$ & $0,0^{2}$ & $0,1 \mathrm{a}$ & $8,365 \mathrm{ab}$ \\
Pioneer 34G82(Cry 1Ab) & $0,3 \mathrm{a}$ & $0,2 \mathrm{a}$ & $8,0 \mathrm{a}$ & $1,2 \mathrm{~b}$ & $8,584 \mathrm{ab}$ \\
Pioneer 34K87(Cry 1Ab) & $0,1 \mathrm{a}$ & $0,3 \mathrm{a}$ & $22,7 \mathrm{a}$ & $1,1 \mathrm{~b}$ & $9,010 \mathrm{a}$ \\
DK 551 (Cry 1Ab) & $0,7 \mathrm{ab}$ & $0,8 \mathrm{a}$ & $22,0 \mathrm{a}$ & $1,7 \mathrm{~b}$ & $8,186 \mathrm{abc}$ \\
MP 704X707 (resistência natural) & $1,9 \mathrm{~b}$ & $1,2 \mathrm{a}$ & $175,6 \mathrm{ab}$ & $3,0 \mathrm{c}$ & - \\
2717 IMI (Cry 1Ab) & $3,4 \mathrm{c}$ & $3,0 \mathrm{~b}$ & $247,9 \mathrm{bc}$ & $7,3 \mathrm{~d}$ & $8,858 \mathrm{a}$ \\
Max 454R176 (Cry 1Ac) & $4,8 \mathrm{~d}$ & $3,1 \mathrm{~b}$ & $190,8 \mathrm{ab}$ & $8,8 \mathrm{e}$ & $6,396 \mathrm{c}$ \\
DK 618 (Cry 1Ac) & $5,5 \mathrm{dc}$ & $3,9 \mathrm{~b}$ & $428,2 \mathrm{~cd}$ & $8,7 \mathrm{c}$ & $8,826 \mathrm{a}$ \\
Garst 8481 (Cry 9C) & $6,8 \mathrm{e}$ & $4,0 \mathrm{~b}$ & $586,4 \mathrm{~d}$ & $8,4 \mathrm{e}$ & $6,708 \mathrm{bc}$ \\
Garst 8539 (Cry 9C) & $6,8 \mathrm{e}$ & $4,1 \mathrm{~b}$ & $586,2 \mathrm{~d}$ & $8,8 \mathrm{e}$ & $7,637 \mathrm{abc}$ \\
\hline
\end{tabular}

${ }^{1}$ Em cada coluna, as médias seguidas pela mesma letra não diferem entre si pelo "Duncan Multiple Range Test" (DMRT, P $\leq 0,05)$.

${ }^{2}$ Os dados originais referentes a essas médias não foram incluídos na análise de variância, por terem sido nulos. As médias dessas variáveis, para os demais tratamentos, foram comparadas à constante zero (média do tratamento 2722 IMI) pelo teste de t. Nessas comparações, não foram observadas diferenças significativas $(\mathrm{P} \leq 0,05)$ entre os tratamentos cujas médias, para o número de insetos, foram 0,2 larvas/planta e para biomassa 8,0, 22,7 e 22,0 mg.

Em geral, os híbridos transgênicos diferiram das respectivas testemunhas (não- $B t$ ), exceto os híbridos Garst 8481 e Garst 8539.

Baseando-se na biomassa das larvas sobreviventes, os dez híbridos $B t$ s ou resistentes avaliados, como no item anterior, foram separados em três grupos, tais como: altamente resistentes - híbridos 2722 IMI, Pioneer 34G82, Pioneer 34K87 e o DK 551 , nos quais a biomassa das larvas sobreviventes foi menos de 22,0 mg; moderadamente resistentes - MP 704 x MP 707, 2717 IMI e Max 454R80, cuja biomassa das larvas sobreviventes variou de 175,6 a 247,9 mg e susceptíveis - DK618 e os híbridos Garst 8481 e 8539 , nos quais a biomassa das larvas sobreviventes variou de 428,2 e 586,4 mg (Tabela 1). Williams et al. (1997 e 1998b) observaram também redução na biomassa de larvas sobreviventes nos genótipos de milho expressando a toxina do Bt Cry $1 \mathrm{~A}(\mathrm{~b})$. 


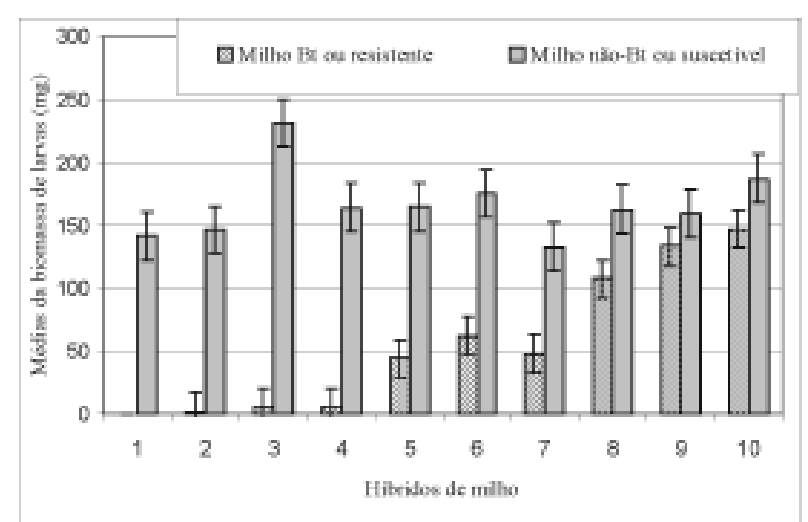

FIGURA 3. Médias ( \pm erro padrão) da biomassa das maiores lagartas coletadas, 15 dias após a infestação, em plantas de milho dos híbridos Bts: 12722 IMI (Cry 1F); 2-P 34G82 (Cry 1Ab); 3P34K87 (Cry 1Ab); 4-DK 551 (Cry 1Ab); 5-MP 704 X MP707 (resistência natural); 6-2717 IMI (Cry 1Ab); 7-M 454R80 (Cry 1Ac); 8-DK 618 (Cry 1Ac); 9-Garst 8481(Cry 9C); 10 Garst 8539 (Cry 9C) e dos não-Bts: 1-2722 IMI; 2 a 4-P 3162; 5Ab42E X SC 229 (suscetível); 6 a 8-P 3162; 9Garst 8481 e 10-Garst 8539, sob infestação artificial da lagarta-do-cartucho do milho, Lincoln, NE, 2000 .

Dano foliar - O dano causado pela LCM, estimado através da escala de notas, foi a variável que apresentou menor erro experimental (Figura 4) e a que melhor discriminou os tratamentos. Os híbridos de milho transgênico - 2722 IMI, Pioneer 34G82 e 34K87, DK 551, 2717 IMI e o híbrido com resistência natural MP 704 X MP 707 diferiram significativamente das testemunhas a menos de $1 \%$ de probabilidade, pelo teste de F. Entretanto, os híbridos Max 454, DK 618 e os Garst 8481 e 8539 não diferiram entre eles (Tabela 1) e nem das respectivas testemunhas não-Bts a esse nível de probabilidade. Usando essa variável como critério, os dez híbridos avaliados podem ser agrupados em cinco categorias (Figura 3): altamente resistente -2722 IMI (Cry 1F); moderadamente resistentes - Pioneer 34G82, 34K87 e DK 551 (Cry 1 Ab), intermediário - MP704 X MP707 (resistência natural); moderadamente susceptível-2717 IMI; e altamente susceptíveis - Max 454, DK 618 e Garst 8481 e 8539 , além de todos os híbridos usados como testemunha.

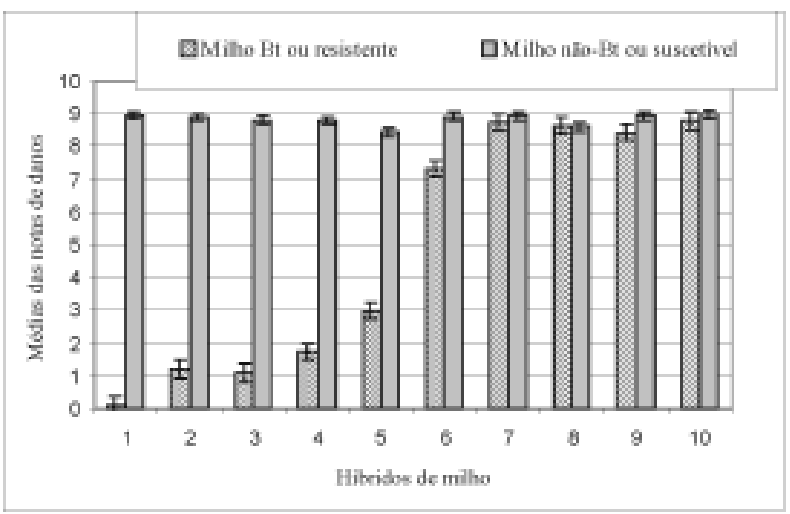

FIGURA 4. Médias ( \pm erro padrão) das notas de danos atribuídas às plantas de milho dos híbridos Bts: 1-2722 IMI (Cry 1F); 2-P 34G82 (Cry 1Ab); 3-P34K87 (Cry 1Ab); 4-DK 551 (Cry 1Ab); 5MP 704 X MP707 (resistência natural); 6-2717 IMI (Cry 1Ab); 7-M 454R80 (Cry 1Ac); 8-DK 618 (Cry 1Ac); 9-Garst 8481(Cry 9C); 10 Garst 8539 (Cry 9C) e dos não-Bts: 1-2722 IMI; 2 a 4-P 3162; 5-Ab42E X SC 229 (suscetível); 6 a 8-P 3162; 9Garst 8481 e 10-Garst 8539, sob infestação artificial da lagarta-do-cartucho do milho, Lincoln, NE, 2000.

Produtividade de grãos - Sendo a produção de grãos resultado de herança quantitativa, muitos fatores afetam essa variável e sua correlação com uma única característica fenotípica geralmente é baixa. Assim, notou-se grande variação nos resultados devido às diferentes bases genéticas de cada híbrido (Figura 5). Em geral, os híbridos de milho transgênico resistentes produziram cerca de $32 \%$ a mais que as testemunhas suscetíveis, com base no peso de grãos corrigido para $13 \%$ de umidade. Esta média está dentro dos limites estimados para as perdas causadas pela LCM (Carvalho, 1970; Cruz \& Turpin, 1983; Williams \& Davis, 1990; Cortez \& Waquil 1997; Cruz et al. 1999). Duas exceções foram 
Waquil et al.

o híbrido MP 704 x MP 707 e suas respectivas testemunhas, que, devido à sensibilidade ao fotoperíodo, não floresceram (produção nula) e o híbrido Garst 8481 , que produziu praticamente igual à testemunha.

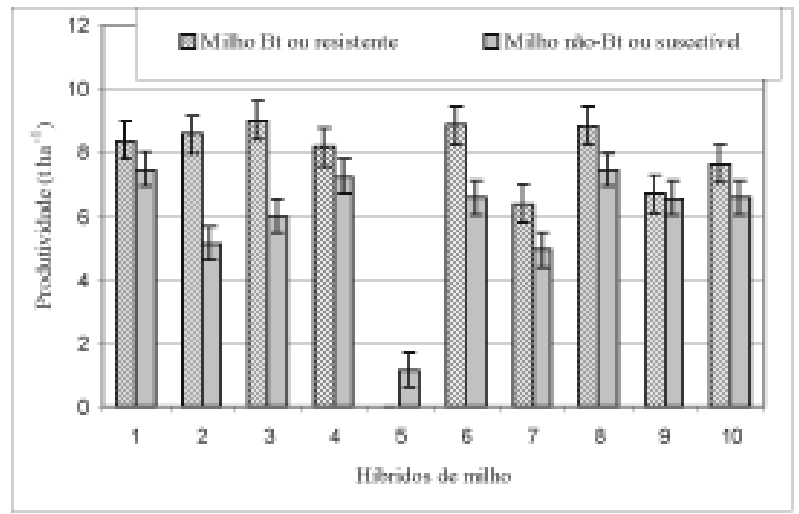

FIGURA 5. Médias ( \pm erro padrão) da produção de grãos corrigidas para $13 \%$ de umidade e para t ha $^{-1}$ dos híbridos de milho Bts: 1-2722 IMI (Cry 1F); 2-P 34G82 (Cry 1Ab); 3-P34K87 (Cry 1Ab); 4-DK 551 (Cry 1Ab); 5-MP 704 X MP707 (resistência natural); 6-2717 IMI (Cry 1Ab); 7-M 454R80 (Cry 1Ac); 8-DK 618 (Cry 1Ac); 9-Garst 8481(Cry 9C); 10 Garst 8539 (Cry 9C) e dos nãoBts: 1-2722 IMI; 2 a 4-P 3162; 5-Ab42E X SC 229 (suscetível); 6 a 8-P 3162; 9-Garst 8481 e 10Garst 8539, sob infestação artificial da lagarta-docartucho do milho, Lincoln, NE, 2000.

Comparando-se a produtividade somente entre os híbridos transgênicos (Tabela 1), destacaram-se os híbridos Pioneer 34K87 (Cry 1Ab) e DK 618 (Cry 1Ac) como os mais produtivos e diferiram significativamente do híbrido Max 454R176 (Cry $1 \mathrm{Ac})$, que apresentou a menor produtividade. Esses resultados mostram que um aumento significativo na produtividade pode ser obtido com a incorporação do gene $b t$. expressando principalmente as toxina Cry $1 \mathrm{~F}$ ou Cry $1 \mathrm{~A}(\mathrm{~b})$, em genótipos com grande potencial de produção.

\section{Conclusões}

Há diferenças significativas entre os eventos $B t$ s incorporados ao milho quanto à resistência à lagarta-do-cartucho, destacando-se o que expressa a toxina Cry $1 \mathrm{~F}$ como altamente resistente, o Cry $1 \mathrm{Ab}$ resistente, o Cry $1 \mathrm{Ac}$ moderadamente resistente e o Cry 9C como suscetível.

Os milhos Bts, expressando as toxinas Cry $1 \mathrm{~F}$ e Cry $1 \mathrm{Ab}$, reduzem tanto a sobrevivência como o desenvolvimento (biomassa) das larvas de Spodoptera frugiperda, sendo que o híbrido expressando a toxina Cry $1 \mathrm{~F}$ mostrou-se praticamente imune ao ataque dessa espécie.

Há diferenças significativas quanto ao nível de redução de área foliar entre os grupos de híbridos, altamente resistentes, resistentes, moderadamente resistentes e suscetíveis.

O híbrido de milho expressando resistência natural apresentou resistência moderada com base em quaisquer das variáveis avaliadas.

Baseando-se na sobrevivência de lagartas aos 10 e 15 dias, biomassa das lagartas sobreviventes aos 15 dias, dano estimado através de escala de notas ou produtividade de grãos, todos os híbridos altamente resistentes, resistentes ou moderadamente resistentes diferiram significativamente das respectivas testemunhas não- $B t$.

Existe interação entre o evento $B t$ e o genótipo, afetando a resposta do inseto quanto à sobrevivência, biomassa das larvas, dano foliar e produtividade de grãos.

\section{Agradecimentos}

Ao Departamento de Entomologia da Universidade de Nebraska, ao LABEX/ARS/USDA, em Lincoln, NE, à Embrapa, ao CNPq, à CAPES, à Monsanto/Dekalb e à DowAgroscience pelo apoio recebido e aos Drs. Elvis A. Heinrichs, Ariovaldo Luchiari, James Overman, Nancy Adams e Peter L. Clark pela colaboração prestada.

\section{Literatura Citada}

BARRY, B. D.; DARRAH, L. L. European corn borer resistance: evaluation of commercial maize 
hybrids and transgenic maize cultivars. In: INTERNATIONAL SYMPOSIUM OF INSECT RESISTANT MAIZE: Recent advances and utilization, 1994, Mexico Proceedings.... México: CIMMYT, 1997. p. 266-270. Edited by J. A. Mihm.

BOULDER, D. Insect pest control by copying nature using genetically engineered crops. Phytochemistry, Elmsford, v. 34, p. 1453-1466, 1993.

CARVALHO, R. P. L. Danos, flutuação populacional, controle e comportamento de Spodoptera frugiperda (Smith, 1797) e susceptibilidade de diferentes genótipos de milho em condições de campo. 1970. 170 f. Tese (Doutorado) - Universidade de São Paulo, Escola Superior de Agricultura Luiz de Queiroz, Piracicaba.

CORTEZ, M. G. R.; WAQUIL, J. M. Influência de cultivar e nível de infestação de Spodoptera frugiperda (J. E. Smith) (Lepidoptera: Noctuidae) no rendimento do sorgo. Anais da Sociedade Entomológica do Brasil, Londrina, v. 26, p. 407410, 1997.

CRUZ, I.; TURPIN, F. T. Yield impact of larval infestation of the fall armyworm (Lepidoptera: Noctuidae) to midwhorl stage of corn. Journal of Economic Entomology, College Park, v. 76, p. 1052-1054, 1983.

CRUZ, I.; FIGUEIREDO, M. L. C.; OLIVEIRA, A. C.; VASCONCELOS, C. A. Damage of Spodoptera frugiperda (Smith) in different maize genotypes cultivated in soil under three levels of aluminum saturation. International Journal of Pest Management, London, v. 45, p. 293-296, 1999.

DAVIS, F. M.; WILLIAMS, W. P. Methods used to screen maize for and to determine mechanisms of resistance to the southwestern corn borer and fall armyworm. In: INTERNATIONAL SYMPOSIUM OF INSECT RESISTANT MAIZE: Recent advances and utilization, 1994. Mexico. Proceedings.... Mexico: CIMMYT, 1997.p 101108. Edited by J. A. Mihm.

DULMAGE, H. T. Insecticidal activity of isolates of Bacillus thuringiensis and their potential to insect control. In: Burgers, H. D. (Ed.). Microbial control of pests and plant disease 1979-1980. London: Academic Press, 1980. p. 193-222.

ESTRUCH, J. J.; CAROZZI, N. B.; DESAI, N.; WARREN, G. W.; DUCK, N. B.; KOZIEL, G. M. The expression of a synthetic CryIA(b) gene in transgenic maize confers resistance to European corn borer. In: INTERNATIONAL SYMPOSIUM OF INSECT RESISTANT MAIZE: Recent advances and utilization, 1994. Mexico. Proceedings.... Mexico: CIMMYT, 1997. p 172-174. Edited by J. A. Mihm.

FEITELSON, J. S.; PAINE, J.; L. KIM. Bacillus thuringiensis: insects and beyond. Biotechnology, New York, v. 10, p. 271-275, 1992.

FOSTER, J. E.; RAMNATH, S. Insect resistance maize: a new paradigm for conducting research. In: INTERNATIONAL SYMPOSIUM OF INSECT RESISTANT MAIZE: Recent advances and utilization, 1994. Mexico.. Proceedings.... Mexico: CIMMYT, 1997. p 180-183. Edited by J. A. Mihm.

HARLAN, J. R. Crops \& Man. Madison: ASA / CSSSA, 1975. $295 \mathrm{p}$.

HEDIN, P. A.; DAVIS, F. M.; WILLIAMS, W. P.; HICKS, R. P.; FISHER, T. H. Hemicellulose is an important leaf-feeding resistance factor in corn to the fall armyworm. Journal of Chemical Ecology, New York, v. 22, p.1655-1668, 1996.

IGNOFFO, C. M.; GREGORY, B. Effects of Bacillus thuringiensis b-exotoxina on larval maturation, adult longevity, fecundity, and egg viability 
in several species of lepidoptera. Environmental Entomology, College Park, v. 1, p. 269-271, 1972.

MAREDIA, K. M. Sustaining host plant resistance derived through conventional and biotechnological means. In: INTERNATIONAL SYMPOSIUM OF INSECT RESISTANT MAIZE: Recent advances and utilization, 1994, Mexico. Proceedings.... Mexico: CIMMYT,1997. p. 175-179. Edited by J. A. Mihm.

MIHM, J. A. Evaluating maize for resistance to tropical stem borers, armyworms and earworm. In: INTERNATIONAL SYMPOSUM ON METHODOLOGIES FOR DEVELOPING HOST PLANT RESISTENCE TO MAIZE INSECTS, 1987, Mexico. Toward insect resistant maize for the third world: Proceedings.... México: CIMMYT, [1989]. p. 109-121.

SAGERS, J.; EDWARDS, M.; BOLAN, B.; WANG, A.; METTLER, I.; BARRETT, L.; GARRETT, C.; MILES, D. Developing maize with resistance to European corn borer In: INTERNATIONAL SYMPOSIUM OF INSECT RESISTANT MAIZE: Recent advances and utilization, 1994, Mexico. Proceedings.... México: CIMMYT,1997. p.163-171. Edited by J.A. Mihm.

VAECK, M.; REYNAERTS, A.; HÖFTE, H.; JANSENS, S.; BEUCKELEER, M. DE; DEAN, C.; ZABEAU, M.; MONTAGU, M. V.; LEEMANS, J. Transgenic plants protected from insect attack. Nature, London, v.327, p.33-37, 1987.

VIANA, P. A.; GAMA, E. E. G. Avaliação de genótipos de milho para a resistência a Spodoptera frugiperda (Smith, 1797) (Lepidoptera: Noctuidae). In: CONGRESSO NACIONAL DE MILHO E SORGO, 17, 1988, Piracicaba. Resumos.... Piracicaba: ESALQ, 1988.p. 60.
VIANA, P. A.; POTENZA, M. R. Estudos dos mecanismos de resistência em populações de milho selecionadas como fontes de resistência à Spodoptera frugiperda. Relatório Técnico Anual do Centro Nacional de Pesquisa de Milho e Sorgo - 1988-91, Sete Lagoas, v.5, p.94-95, 1992.

WAQUIL, J. M.; VIANA, P. A.; LORDELO, A. I.; .CRUZ, I.; OLIVEIRA, A. C. Controle da lagarta-do-cartucho em milho com inseticidas químicos e biológicos. Pesquisa Agropecuária Brasileira, Brasília, v.17, n.2, p.163-166, 1982.

WILLIAMS, W. P.; DAVIS, F. M. Registration of Mp 704 germplasm line of maize. Crop Science, Madison, v.22, p.1269-1270, 1982.

WILLIAMS, W. P.; DAVIS, F. M. Registration of Mp 705, Mp 706, and Mp 707 germplasm lines of maize. Crop Science, Madison, v.24, p.1217, 1984.

WILLIAMS, W. P.; DAVIS, F. M. Response of corn to artificial infestation with fall armyworm and southwestern corn borer larvae. Southwestern Entomologist, College Station, v.15, p.163-166, 1990.

WILLIAMS, W. P.; DAVIS, F. M.; OVERMAN, J. L.; BUCKLEY P. M. Enhancing inherent fall armyworm (Lepidoptera: Noctuidae) resistance of corn with Bacillus thuringiensis genes. Florida Entomology, Gainsville, v.82, n.2, p.272-277, 1999.

WILLIAMS, W. P.; DAVIS, F. M.;. BUCKLEY, P. M.; HEDIN, P. A.; BAKER, G. T.; LUTHE, D. $\mathrm{S}$. Factors associated with resistance to fall armyworm .(Lepidoptera: Noctuidae), and southwestern corn borer (Lepidoptera: Crambidae) in corn at different vegetative stage. Journal of Economic Entomology, College Park, v.91, p.1471-1480, 1998a.

WILLIAMS, W. P.; BUCKLEY, P. M.; SAGERS, J. B.; HANTEN, J. A. Evaluation of transgenic corn 
for resistance to corn earworm.(Lepidoptera: southwestern corn borer. Crop Science, Madison, Noctuidae), fall armyworm. (Lepidoptera: v.37, p.957-962, 1997.

Noctuidae), and southwestern corn borer (Lepidoptera: Crambidae) in a laboratory bioassay. Journal of Agricultural Entomology, Clemson, v.15, p.105-112, 1998b.

WILLIAMS, W. P.; DAVIS, F. M.; WINDHAM, G. L. Registration ofMp 708 germplasm line of maize. Crop Science, Madison, v.30, p.757, 1990. WILLIAMS, W. P.; SAGERS, J. B.; HANTEN, J. WILLIAMS, W. P.; DAVIS, F. M.; WISEMAN, A.; DAVIS, F. M.; BUCKLEY, P. M. Transgenic B. R. Fall armyworm resistance in corn and its corn evaluated for resistance to fall armyworm and suppression of larval survival and growth. Agronomy Journal, Madison, v.75, p.831-832, 1983. 